\title{
Acute spinal cord injury: monitoring the lumbar cerebrospinal fluid provides limited information about the injury site
}

${ }^{1}$ Florence R.A. Hogg MRCS, ${ }^{1}$ Mathew J. Gallagher MRCS, ${ }^{1}$ Siobhan Kearney RN, ${ }^{2}$ Argyro Zoumprouli MD, ${ }^{1 *}$ Marios C. Papadopoulos MD, ${ }^{1 \dagger} *$ Samira Saadoun $\mathrm{PhD}$

*Co-senior authors

${ }^{1}$ Academic Neurosurgery Unit, St. George's, University of London, Cranmer terrace, Tooting London SW17 0RE, U.K.

${ }^{2}$ Neuro-intensive Care Unit, St. George's Hospital, London, U.K.

'Corresponding author: S. Saadoun, ssaadoun@sgul.ac.uk

Running title: Monitoring after spinal cord injury

Table of contents title: Monitoring from injury site vs. lumbar space after spinal cord injury

Study funding: Supported by the Wings for Life Spinal Cord Research Foundation and the Neurosciences Research Foundation (Fletcher Fund).

\section{Abbreviations:}

AIS $=$ American spinal injuries association Impairment Scale 
CSFP $=($ lumbar $)$ cerebrospinal fluid pressure

$\mathrm{ICU}=$ Intensive care unit

ISCoPE $=$ injured spinal cord pressure evaluation study

ISNCSCI = International standards for neurological classification of spinal cord injury

ISP $=$ intraspinal pressure

$\mathrm{MAP}=$ mean arterial pressure

$\mathrm{MD}=$ microdialysis

$\mathrm{SCPP}=$ spinal cord perfusion pressure

$\mathrm{SCPP}_{\mathrm{opt}}=$ optimum spinal cord perfusion pressure

$\mathrm{sPRx}=$ spinal pressure reactivity index

$\mathrm{TSCI}=$ traumatic spinal cord injury 
Florence Hogg MB ChB, Doctoral Research student, Academic Neurosurgery Unit, Molecular and Clinical Sciences Institute, St. George's, University of London, London SW17 0RE, United Kingdom. Tel. +44(0)2087254179; Email. fhogg@,sgul.ac.uk

Mathew J. Gallagher MB ChB, Doctoral Research student, Academic Neurosurgery Unit, Molecular and Clinical Sciences Institute, St. George's, University of London, London SW17, United Kingdom. Tel. +44(0)2087254179; Email. magallag@sgul.ac.uk

Siobhan Kearney RN, Research Nurse Academic Neurosurgery Unit, Molecular and Clinical Sciences Institute, St. George's, University of London, London SW17, United Kingdom. Tel. +44(0)2087254179; Email.siobhan.kearney@stgeorges.nhs.uk

Argyro Zoumprouli MD, Consultant in Neuro-anaesthesia, St. George's Hospital, Tooting, London SW17 0QT, United Kingdom. Tel. +44(0)2087254179; Email. azoumprouli@gmail.com

Marios C. Papadopoulos MD, Professor of Neurosurgery, Academic Neurosurgery Unit, Molecular and Clinical Sciences Institute, St. George's, University of London, London SW17 0RE, United Kingdom. Tel. +44(0)2087254179; Email. mpapadop@ssul.ac.uk

Samira Saadoun PhD, Senior Lecturer in Neuroscience Academic Neurosurgery Unit, Molecular and Clinical Sciences Institute, St. George's, University of London, London SW17 0RE, United Kingdom. Tel. +44(0)2087254179; Email.ssaadoun@sgul.ac.uk 


\begin{abstract}
In some centers, monitoring the lumbar cerebrospinal fluid (CSF) is used to guide management of patients with acute traumatic spinal cord injuries (TSCI) and draining lumbar CSF to improve spinal cord perfusion. Here, we investigate whether the lumbar CSF provides accurate information about the injury site and the effect of draining lumbar CSF on injury site perfusion. In 13 TSCI patients, we simultaneously monitored lumbar CSF pressure (CSFP) and intraspinal pressure (ISP) from the injury site. Using CSFP or ISP, we computed spinal cord perfusion pressure (SCPP), vascular pressure reactivity index (sPRx) and optimum $\operatorname{SCPP}\left(\mathrm{SCPP}_{\mathrm{opt}}\right)$. We also assessed the effect on ISP of draining $10 \mathrm{~mL}$ CSF. Metabolites at the injury site were compared with metabolites in the lumbar CSF. We found that ISP was pulsatile, but CSFP had low pulse pressure and was non-pulsatile $21 \%$ of the time. There was weak or no correlation between CSFP versus ISP $(\mathrm{R}=-0.11), \mathrm{SCPP}_{(\mathrm{csf})}$ versus $\mathrm{SCPP}_{(\mathrm{ISP})}$ $(\mathrm{R}=0.39)$ and $\mathrm{sPRx}\left(\right.$ csf) versus $\mathrm{sPRx} \mathrm{x}_{(\mathrm{ISP})}(\mathrm{R}=0.45) . \mathrm{CSF}$ drainage caused no significant change in ISP in $7 / 12$ patients, a significant drop by $<5 \mathrm{mmHg}$ in $4 / 12$ patients and by $\sim 8 \mathrm{mmHg}$ in 1/12 patient. Metabolite concentrations in the CSF versus injury site did not correlate for lactate $(\mathrm{R}=0.00)$, pyruvate $(\mathrm{R}=-0.12)$ or lactate-to-pyruvate ratio $(\mathrm{R}=-0.05)$ with weak correlations noted for glucose $(\mathrm{R}=0.31)$, glutamate $(\mathrm{R}=0.61)$ and glycerol $(\mathrm{R}=0.56)$. We conclude that, after a severe TSCI, monitoring from the lumbar CSF provides only limited information about the injury site and that lumbar CSF drainage does not effectively reduce ISP in most patients.
\end{abstract}

Manuscript keywords: Cerebrospinal fluid, Clinical management of CNS injury, Microdialysis, Traumatic spinal cord injury 


\section{INTRODUCTION}

Traumatic spinal cord injury (TSCI) is a devastating event that affects $\sim 180,000$ people globally each year. ${ }^{1}$ Prognosis is poor: more than $1 / 3$ of patients have complete paraplegia or quadriplegia, less than $1 \%$ are discharged neurologically normal and their life expectancy is below the national average. ${ }^{2}$ There is no treatment proven to improve outcome after TSCI. ${ }^{3}$

To optimize the early management of TSCI, we developed multi-modality monitoring from the injury site in patients in the intensive care unit (ICU) ${ }^{4}$ we monitor intra-spinal pressure (ISP) and compute spinal cord perfusion pressure (SCPP) as mean arterial pressure (MAP) minus ISP. ${ }^{5-7}$ We also monitor injury site metabolism by microdialysis (MD). ${ }^{8,9}$ These techniques are safe and analogous to multimodality monitoring in traumatic brain injury. ${ }^{10}$ Our data show that ISP and SCPP are clinically important parameters that correlate with injury site metabolism, ${ }^{11}$ neurological status ${ }^{12}$ and long-term neurological outcome. ${ }^{6}$

Monitoring from the injury site allows intervention to reduce secondary damage, e.g. increasing SCPP to reduce cord ischemia. We showed that low SCPP and high SCPP may both be detrimental and proposed the concept of optimum SCPP $\left(\mathrm{SCPP}_{\mathrm{opt}}\right)$ as the SCPP that maximises vascular reactivity. ${ }^{12}$ ISP monitoring allows individualized management by targeting each patient's $\mathrm{SCPP}_{\text {opt }}$ rather than applying the same MAP to all. ${ }^{5} \mathrm{MD}$ monitoring revealed that some periods of high ISP are associated with hypometabolim (low tissue glucose, high LPR, high glutamate, high glycerol) and may benefit from increasing SCPP, whereas other periods of high ISP are associated with hypermetabolism (low tissue glucose, LPR, low glutamate, low glycerol) and thus increasing SCPP may be detrimental. ${ }^{8,9} \mathrm{MD}$ monitoring has also revealed that fever is associated with metabolic derangement at the injury site. Thus, monitoring from the injury site may help clinical management $\left(\mathrm{see}^{13}\right)$.

Some doctors monitor lumbar cerebrospinal fluid pressure (CSFP) rather than ISP and compute $\mathrm{SCPP}_{(\mathrm{csf})}$ as MAP - CSFP rather than $\mathrm{SCPP}_{(\mathrm{ISP})}$ as MAP - ISP. ${ }^{14-16}$ Monitoring from 
the lumbar CSF is achieved by placing a lumbar catheter, which can easily be done in ICU. The lumbar catheter is also used therapeutically to drain CSF to increase cord perfusion in after TSCI and in patients undergoing aortic aneurysm repair. ${ }^{17-20}$ In contrast, monitoring from the injury site requires surgery to expose the dura at the injury site and insert probes intradurally under a microscope. Thus, monitoring from the lumbar CSF compartment is less invasive and easier to accomplish than injury site monitoring.

In this study, we monitored simultaneously from the injury site and from the lumbar CSF space in patients with acute, severe TSCI to define the relationship between CSFP versus ISP, $\mathrm{SCPP}_{(\mathrm{csf})}$ versus $\mathrm{SCPP}_{(\mathrm{ISP})}$ and metabolite levels in the lumbar CSF versus injury site. We also determined the effect of draining lumbar CSF on ISP.

\section{MATERIALS AND METHODS}

Institutional Research Board Approvals. Approvals for the Injured Spinal Cord Pressure Evaluation (ISCoPE) study including the consent form and patient information sheet were obtained by the St Georges Joint Research Office and the National Research Ethic Service Camberwell St Giles Committee (No 10/H0807/23). ISCoPE is registered at www.clinical trials.gov as NCT02721615.

Inclusion/Exclusion Criteria. We recruited TSCI patients who were enrolled into the ISCoPE trial in the period October 2017 - February 2019. Inclusion criteria for ISCoPE are: severe TSCI defined as AIS grades A - C, age 18 - 70 years and surgery performed within 72 hours of TSCI. Exclusion criteria are: major co-morbidities, inability to obtain consent and penetrating SCI. 
Clinical examination and imaging. All patients were admitted to the neurosurgical unit at St. George's Hospital and underwent ISNCSCI AIS assessment by a neurosurgical resident trained in AIS. All patients had CT and MRI of the spine imaging before surgery and within two weeks after surgery. We measured the longitudinal extent of T2 cord signal change on the pre-operative MRI as a biomarker of cord edema.

Probe insertion. Surgical decompression and spinal instrumentation were performed based on patient requirements and surgeon preference. During surgery an ISP probe (Codman Microsensor Transducer ${ }^{\circledR}$, Depuy Synthes, Leeds, UK) and a MD catheter (CMA61: CMA microdialysis AB, Solna, Sweden) were placed intradurally on the surface of the injured cord at the site of maximal cord swelling. The dural opening was sutured and supplemented with fibrin glue (Tisseel®, Baxter, UK). At the end of surgery, a lumbar catheter was inserted at the L4/5 or L3/4 disc levels and advanced $15-20 \mathrm{~cm}$ from the skin edge. Fig. 1A shows the setup.

Monitoring and lumbar CSF drainage. The ISP probe was connected to a Codman ICP box linked via a ML221 amplifier to a PowerLab running LabChart v.7.3.5 (AD Instruments, Oxford, UK). The lumbar catheter was connected to an external drainage system (Integra ${ }^{\text {TM }}$ AccuDrain ${ }^{\circledR}$ External CSF Drainage System) which was attached to a pressure transducer and closed to the drain. It was then connected to the Philips Intellivue MX800 bedside monitoring system (Philips, Guildford, UK) and in turn connected to the PowerLab system. Nurses were instructed to keep the transducer at the level of the lumbar spine. Blood pressure was recorded from a radial artery catheter connected to the Philips Intellivue MX800 bedside monitoring system (Philips, Guildford, UK) and in turn connected to the PowerLab system. ISP and arterial blood pressure signals were sampled at $1 \mathrm{kHz}$ and patients were monitored 
for up to 7 days. With the patient lying flat, up to $10 \mathrm{ml} \mathrm{CSF}$ was drained each time from the lumbar catheter to assess the effect on ISP. No more than $30 \mathrm{ml}$ of CSF was drained in a 24hour period.

Microdialysis setup and analysis. MD was started postoperatively in the ICU as described. ${ }^{8}$, ${ }^{9,11} \mathrm{CNS}$ perfusion fluid (CMA microdialysis $\mathrm{AB}$ ) was perfused at $0.3 \mu \mathrm{L} / \mathrm{min}$ using the CMA106 pump (CMA microdialysis AB). MD vials were changed hourly and analyzed using ISCUS Flex (CMA microdialysis AB) for the following metabolites: glucose, lactate, pyruvate, glycerol, glutamate and LPR. Samples of CSF were collected at each CSF drainage and were used to measure the same metabolites. CSF metabolite levels were then compared against corresponding metabolite levels at the injury site obtained from the same hour of sampling.

Signal analysis. Data was analysed using Labchart v.8 (AD Instruments, Oxford, UK) and $\mathrm{ICM}+$ (www.neurosurg.cam.ac.uk/icmplus) to compare ISP versus CSFP signals including morphology of individual waveforms, entire period mean values and duration of pulseless CSFP. We also computed the running correlation between CSFP and ISP defined as the Pearson correlation coefficient of the preceding 60 one-second averages of CSFP $v s$. ISP, updated each minute. We argued that the timing of the ISP and CSFP waveforms will be greatly influenced by compliance, i.e. a more compliant compartment will transmit pulses more slowly than a less compliant one. We thus also computed two elements of pulse wave timing: the latency $(\lambda)$ between the onset of an ISP waveform and the onset of the corresponding CSFP waveform as well as the slope of each pulse wave $(\delta \mathrm{P} / \delta \mathrm{T})$. Frequencydomain analysis of the ISP and CSFP waveforms was performed using a Fast Fourier Transformation to determine cardiac and respiratory contributions to these signals. Three 
two-hour traces of waveform signals were analyzed for each patient corresponding to periods that the CSFP was very-, minimally- and non- pulsatile. ISP and CSFP were also used to compute the following: $\mathrm{SCPP}=\mathrm{MAP}-\mathrm{ISP}, \mathrm{SCPP}(\mathrm{csf})=\mathrm{MAP}-\mathrm{CSFP}, \mathrm{sPR}_{\mathrm{ISP}}=$ running correlation coefficient between MAP and ISP, $\mathrm{sPRx}_{(\mathrm{csf})}=$ running correlation coefficient between MAP and CSFP, $\mathrm{SCPP}_{\mathrm{opt}(\mathrm{ISP})}=\mathrm{SCPP}$ at minimum $\mathrm{sPRx}(\mathrm{ISP})$, and $\mathrm{SCPP}_{\mathrm{opt}(\mathrm{csf})}=$ $\mathrm{SCPP}_{(\mathrm{csf})}$ at minimum sPRx $\mathrm{x}_{(\mathrm{csf})}$.

Statistics. The Pearson coefficient was used to examine the correlations between CSFP versus ISP, $\mathrm{SCPP}_{(\mathrm{csf})}$ versus $\mathrm{SCPP}_{(\mathrm{ISP})}, \mathrm{SCPP}_{\mathrm{opt}(\mathrm{csf})}$ versus $\mathrm{SCPP}_{\mathrm{opt}(\mathrm{ISP})}, \mathrm{sPRx}_{(\mathrm{csf})}$ versus $\mathrm{xPRx}_{(\mathrm{ISP})}$, metabolite concentrations in lumbar CSF versus microdialysate as well as extent of cord edema (length of T2 signal abnormality on pre-operative MRI) versus mean Pearson correlation coefficient between CSFP and ISP. The change in ISP ( $\triangle$ ISP) as a result of draining lumbar CSF was defined as 15 -minute mean ISP prior to drainage minus 15 -minute mean ISP ten minutes after drainage and was compared using Student's t-test for all the repeats in each patient. $\delta \mathrm{P} / \delta \mathrm{T}$ values for CSP versus ISP were compared using Student's ttest. The different $\lambda$ groups were compared by multiple Student's t-tests with Bonferroni correction.

\section{RESULTS}

Patient Demographics. Data were collected from 13 consecutive patients aged $26-67$ years (mean 47). Most (62\%) patients had complete (AIS A) injuries and most (70\%) had cervical injuries. All patients underwent posterior surgical bony decompression including laminectomy and fusion with $31 \%$ also requiring concurrent anterior stabilisation. Mean duration of follow-up was about half a year. At follow-up, most patients (54\%) had improved by one of more AIS grade, some (38\%) remained the same and one patient ( $8 \%$ ) 
deteriorated by one AIS grade. Mean duration of monitoring was $4-5$ days and mean number of MD-CSF matched sample pairs per patient was eight. Details are in Table 1.

Complications. In three patients $(23 \%)$, the lumbar drain stopped working and was re-sited or removed. One patient ( $8 \%$ ) with poorly-controlled diabetes mellitus developed a postoperative E. Coli septicaemia from urosepsis followed by E. Coli wound infection 17 days after surgery; the infection was eliminated with wound washout plus six weeks of intravenous antibiotics. Of note, this was the only ISCoPE patient who developed a wound infection out of the 76 who underwent multi-modality injury site monitoring to date (2010 9) giving an overall infection risk of $1.3 \%$. CSF leak from the probe skin exit site was observed in 4/13 patients (31\%) and was successfully stopped by placing additional skin sutures. Six of the thirteen patients (46\%) had asymptomatic, non-compressive pseudomeningoceles noted on post-operative MRI, done within 2-3 months of TSCI, which resolved on the 1-year post-operative MRI. Details are in Table 2.

ISP versus CSFP waveform shapes. Morphologically, the ISP waveforms were comparable to the intracranial pressure waveforms with three major peaks: percussion, tidal and dicrotic. ${ }^{21}$ In contrast, the CSFP waveforms appeared flatter than ISP and less pulsatile with non-pulsatile periods (Figs. 1B-D). Additional comparisons between ISP and CSFP waveforms are in the supplement. Frequency domain analysis for ISP revealed respiratory and heartbeat peaks (+ harmonics) with either peak the tallest. Flat CSFP had no frequency peaks, minimally pulsatile CSFP had only the respiratory peak whereas more pulsatile CSFP had both respiratory and heartbeat peaks with the respiratory peak always the tallest. Timing analysis revealed significantly steeper $\delta \mathrm{P} / \delta \mathrm{T}$ slope for ISP than CSFP waveforms and 
significant delay, by $>100 \mathrm{~ms}$ in most cases, between the onset of the CSFP pulse compared with the corresponding ISP pulse.

ISP versus CSFP signals. When averaged over the entire monitoring period, ISP was higher than the CSFP by $\sim 5 \mathrm{mmHg}$. A plot of average CSP versus average ISP for the 13 patients showed no overall correlation: in 6/13 patients, mean ISP - mean CSFP $>5 \mathrm{mmHg}$, in 2/13 patients mean CSFP - mean ISP $>5 \mathrm{mmHg}$ and in $5 / 13$ patients mean ISP and mean CSFP were within $5 \mathrm{mmHg}$ (Fig. 2A). Closer inspection of these signals revealed periods when the ISP and CSFP pulsations appeared uncorrelated and other periods when the CSFP and the ISP pulsations appeared almost identical (Fig. 2B). To evaluate this time-variability in the correlation between the CSFP and the ISP signals, we computed their running correlation coefficient (Fig. 2C-D). The running correlation coefficient was $>0.7$ for $>75 \%$ of the time in $3 / 13$ patients ( 2 cervical +1 thoracic injuries), $25-75 \%$ of the time in $3 / 13$ patients (all cervical) and $<25 \%$ of the time in $7 / 13$ patients ( 4 cervical +2 thoracic +1 conus). We noted periods of positive CSFP versus ISP correlation, periods of no correlation and periods of anti-correlation. There was no significant difference in the running coefficient between cervical versus thoracolumbar TSCIs.

SCPP, sPRx, $\mathbf{S C P P}_{\text {opt }}$ and metabolites. Overall, there was no significant correlation between $\mathrm{SCPP}_{(\mathrm{csf})}$ versus $\mathrm{SCPP}(\mathrm{ISP}), \mathrm{sPRx}_{(\mathrm{csf})}$ versus $\mathrm{sPRx} \mathrm{x}_{(\mathrm{ISP})}$ or $\mathrm{SCPP}_{\text {opt(csf) }}$ versus $\mathrm{SCPP}_{\text {opt(ISP) }}$ (Fig. 3). Also, the overall levels of metabolites measured from the injury site by microdialysis versus the corresponding levels in the lumbar CSF did not significantly correlate for lactate, pyruvate and LPR, though there were significant, albeit weak, positive correlations for glucose, glutamate and glycerol (Fig. 4). When we examined individual 
patients, significant positive correlations between injury site and lumbar CSF levels were found in 8/12 for glucose, 8/12 for glutamate, 6/12 for glycerol.

Effect on ISP of CSF drainage. In 12/13 patients, we drained $\sim 10 \mathrm{~mL}$ CSF through the lumbar catheter on several occasions. CSF drainage had variable effect on ISP: On average, in $7 / 12$ patients there was no change in ISP, in $4 / 12$ patients there was a significant small reduction in ISP by $<5 \mathrm{mmHg}$ and in $1 / 12$ patients there was a large drop in ISP by $5-10$ mmHg (Fig. 5). In 3/12 patients, on some occasions, we observed the phenomenon of 'dry tap', where CSF would not be drained even though the lumbar catheter was patent (i.e. able to flush and transduced a pressure wave). This resolved in $2 / 3$ patients, but persisted in $1 / 3$ (patient 10) after day 2 even though the lumbar drain appeared in the spinal canal on the postoperative CT.

Cord swelling and CSFP versus ISP Correlation. We hypothesized that if the injured cord is not very swollen, then it will be surrounded by CSF and, therefore, the ISP and the CSFP signals will be similar, i.e. their correlation will be high. Conversely, if the cord is very swollen, it will become compressed against the dura. In this case, the ISP is the pressure of the swollen cord against the dura, whereas the CSFP is the pressure in the lumbar CSF and, therefore, there will be loss of correlation between CSFP versus ISP. The longitudinal extent of cord signal change on pre-operative T2 MRI, used as a measure of cord edema, inversely correlated with the mean CSFP versus ISP correlation coefficient (Fig. 6). In other words, patients with less swollen spinal cords had stronger positive correlations between their CSFP and their ISP signals thus supporting our hypothesis.

\section{DISCUSSION}


Our key finding is that, after acute severe TSCIs, the values of physiological (i.e. ISP, SCPP, sPRx, $\mathrm{SCPP}_{\mathrm{opt}}$ ) and biochemical (i.e. glucose, lactate, pyruvate, LPR, glutamate, glucose) parameters measured at the injury site markedly differ from equivalent measurements from the lumbar CSF. Lack of correlation between ISP and CSFP likely occurs when the injured cord is compressed against the dura, i.e. there is no CSF around the injury site. The presence of periods with high correlation between ISP and CSFP suggests that cord compression is a dynamic process. These ideas are supported by our earlier finding of a pressure profile along the injured cord ${ }^{12,22}$ and our current observation that patients with more cord swelling on preoperative MRI have poorer correlation between ISP and CSFP.

ISP and CSFP pulse timings suggest that the injury site and the lumbar CSF have different physical properties. CSFP pulses have lower $\delta \mathrm{P} / \delta \mathrm{T}$ and lag behind ISP pulses; this means that ISP pulses are in a 'tight' compartment (low compliance, cord compressed against dura), but CSFP pulses are in a 'loose' compartment (lumbar CSF). ${ }^{23}$ ISP has two prominent frequency peaks (cardiac, respiratory), as previously shown, ${ }^{12,21}$ but CSFP may be flat (no peaks), a little pulsatile (respiratory peak only) or more pulsatile (two peaks, respiratory taller than cardiac). Lack of lumbar CSF pulsatility in TSCI was also noted by Kwon et al. who found correlation with cord compression on $\mathrm{MRI}^{16}$. We propose that the swollen cord inhibits the caudal transmission of cord and CSF pulsations to the lumbar CSF thus causing CSFP pulsatility to diminish. In our ventilated patients, lung pressure fluctuations likely produce venous pressure fluctuations that are transmitted to the CSFP regardless of cord compression. This may explain why the respiratory frequency peak in CSFP often persists even when the cardiac frequency peak has disappeared.

Over the last few years, we showed how the ISP signal can be used to derive several physiological parameters (SCPP, $\mathrm{SPRx}$ and $\left.\mathrm{SCPP}_{\mathrm{opt}}\right)^{12,21,24,25}$ that correlate with injury site metabolism, ${ }^{11}$ acute neurological status ${ }^{12}$ and long-term neurological outcome ${ }^{6}$ and may 
guide the management of TSCI patients in ICU. We observed major differences between these parameters computed using ISP versus CSFP. The differences arise because of the overall lack of correlation between ISP and CSFP. During periods that the spinal cord is not

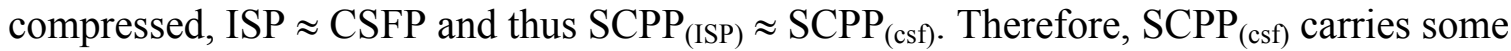
information about $\mathrm{SCPP}_{(\mathrm{ISP})}$; this may explain why $\mathrm{SCPP}_{(\mathrm{csf})}$ has some predictive power in $\mathrm{TSCI}^{15}$. Neurological outcome correlates better with $\mathrm{SCPP}_{(\mathrm{ISP})}{ }^{6}$ than $\mathrm{SCPP}_{(\mathrm{csf})},{ }^{15}$ probably

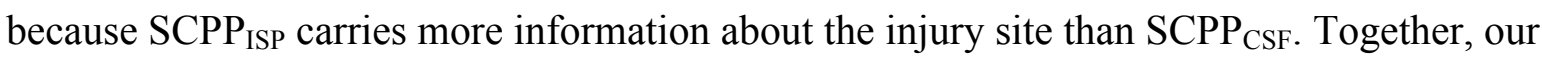
findings suggest that CSFP monitoring is less cumbersome than ISP monitoring, but cannot reliably estimate ISP, SCPP, $\mathrm{sPRx}$ or $\mathrm{SCPP}_{\text {opt }}$.

Lumbar CSF drainage has been used to improve cord perfusion after TSCI in patients ${ }^{16}$ and pig models. ${ }^{26}$ In our study, CSF drainage did not reliably reduce ISP in most TSCI patients, probably because of the lack of CSF around the injury site. Our observation of 'dry taps' on several occasions, also noted by Kwon et al., ${ }^{16}$ supports the idea of a block in the flow of CSF caused by the swollen cord compressed against the dura. In patients with CSF around the injured cord, lumbar CSF drainage is predicted to reduce ISP (Patient 4, Fig. 5). Even in this patient, however, ISP decreased only on some occasions, which suggests that the cord is intermittently compressed. Ways to reliably increase SCPP include vasopressors to increase $\mathrm{MAP}^{12}$ or expansion duroplasty to reduce ISP. ${ }^{27}$

Tissue MD is widely used when managing patients with brain injuries. ${ }^{28}$ We showed that MD also provides clinically important information after TSCI. ${ }^{8,9}$ Our data suggest that metabolite levels at the injury site differ from corresponding levels in the lumbar CSF. An explanation is that the MD catheter samples metabolites from the extracellular space at the injury site, but metabolites are shed into the lumbar CSF not only from the injury site, but also from the cord below. Differences in metabolite levels at the injury site versus lumbar CSF were more pronounced for lactate, pyruvate and LPR probably because the cord below 
the injury has healthier metabolism than the injury site. Tissue [glucose] at the injury site correlated with lumbar CSF [glucose]; a possible explanation is that both concentrations are influenced by serum [glucose]. ${ }^{8,29}$ [Glutamate] and [glycerol] at the injury site also correlated with lumbar CSF levels; this may be because the normal cord does not release glutamate or glycerol, i.e. the glutamate and glycerol in the lumbar CSF originated entirely from the injury site. Despite reaching statistical significance, the correlations of injury site versus lumbar CSF for [glucose], [glutamate] and [glycerol] were weak with large inter-patient variability.

By analogy with intracranial pressure monitoring for brain injury, ISP monitoring for TSCI may be helpful to guide management in the most severely injured patients. ${ }^{13}$ To date, we have only monitored ISP and MD in patients with severe TSCI, i.e. AIS A, B or C at baseline. Potential risks of injury site monitoring include mechanical spinal cord damage, subdural haematoma, dural CSF leak causing pseudomeningocele or leak though the skin, meningitis and probe retention requiring surgery to remove. In a study of 42 patients who had ISP monitoring, complications were probe displacement in $2.4 \%$, CSF leak requiring wound re-suturing in $7.1 \%$ and asymptomatic pseudomeningocele in $19.0 \%$ that resolved within 6 months. ${ }^{10}$ There were no serious probe-related complications such as meningitis, wound infection, subdural hematoma, wound breakdown or neurological deterioration.

Based on our findings, we urge caution when interpreting data obtained from the lumbar CSF in TSCI patients. To monitor pathological events within the injured cord, we advocate directly accessing the injury site, which is safe ${ }^{10}$ and may be used to obtain multimodality data including ISP, SCPP, sPRx, SCPP ${ }_{\text {opt }}$ and MD., 12

\section{CONCLUSIONS}

In 13 patients with TSCI, monitoring from the injury site was compared with monitoring from the lumbar CSF. The effect of draining lumbar CSF on injury site perfusion was also 
assessed. We conclude that monitoring from the lumbar CSF offers limited information about the injury site and that drainage of lumbar CSF does not improve cord perfusion in most patients.

\section{FUNDING}

Supported by grants awarded to MCP and SS from Wings for Life Spinal Cord Research Foundation and to MCP from the Neurosciences Research Foundation (Fletcher Fund). FRAH is a Royal College of Surgeons of England research fellow. MJG is supported by the Neurosciences Research Foundation (Fletcher Fund). SK is supported by NIHR CRN.

\section{ACKNOWLEDGEMENTS}

We thank the neurosurgeons at St. George's Hospital, King's College Hospital and Hurstwood Park Neurological Centre as well as the spinal orthopaedic surgeons at St. George's Hospital who helped recruit patients. The neuroanaesthetic, neurointensive care and operating theatre staff at St. George's Hospital helped with data collection.

\section{AUTHOR CONTRIBUTIONS STATEMENT}

FRAH collected the data with help from MG and SK. MCP performed the surgical procedures. AZ was the anesthesiologist. $\mathrm{MCP}$ and $\mathrm{AZ}$ looked after the patients after surgery. FRAH and SS analyzed the data and produced the figures. SS wrote the manuscript. FRAH, MG, SK, AZ and MCP contributed to the manuscript. SS supervised the project.

\section{AUTHOR DISCLOSURES}

No competing financial interests exist. 


\section{REFERENCES}

1. Lee, B.B., Cripps, R.A., Fitzharris, M. and Wing, P.C. (2014). The global map for traumatic spinal cord injury epidemiology: update 2011, global incidence rate. Spinal Cord $52,110-116$.

2. Centre, N.S.S. (2014). Spinal cord injury facts and figures at a glance. J Spinal Cord Med $37,659-660$.

3. Wilson, J.R., Forgione, N. and Fehlings, M.G. (2013). Emerging therapies for acute traumatic spinal cord injury. CMAJ 185, 485-492.

4. Saadoun, S. and Papadopoulos, M.C. (2016). Spinal cord injury: is monitoring from the injury site the future? Crit Care 20, 308.

5. Chen, S., Smielewski, P., Czosnyka, M., Papadopoulos, M.C. and Saadoun, S. (2017). Continuous Monitoring and Visualization of Optimum Spinal Cord Perfusion Pressure in Patients with Acute Cord Injury. J Neurotrauma 34, 2941-2949.

6. Saadoun, S., Chen, S. and Papadopoulos, M.C. (2017). Intraspinal pressure and spinal cord perfusion pressure predict neurological outcome after traumatic spinal cord injury. J Neurol Neurosurg Psychiatry 88, 452-453.

7. Hogg, F.R.A., Gallagher, M.J., Chen, S., Zoumprouli, A., Papadopoulos, M.C. and Saadoun, S. (2019). Predictors of Intraspinal Pressure and Optimal Cord Perfusion Pressure After Traumatic Spinal Cord Injury. Neurocrit Care 30, 421-428.

8. Phang, I., Zoumprouli, A., Papadopoulos, M.C. and Saadoun, S. (2016). Microdialysis to Optimize Cord Perfusion and Drug Delivery in Spinal Cord Injury. Ann Neurol 80, 522-531.

9. Chen, S., Phang, I., Zoumprouli, A., Papadopoulos, M.C. and Saadoun, S. (2016).

Metabolic profile of injured human spinal cord determined using surface microdialysis. $\mathrm{J}$ Neurochem 139, 700-705. 
10. Phang, I., Zoumprouli, A., Saadoun, S. and Papadopoulos, M.C. (2016). Safety profile and probe placement accuracy of intraspinal pressure monitoring for traumatic spinal cord injury: Injured Spinal Cord Pressure Evaluation study. J Neurosurg Spine 25, 398-405. 11. Gallagher, M.J., Zoumprouli, A., Phang, I., Schwab, J.M., Kopp, M.A., Liebscher, T., Papadopoulos, M.C. and Saadoun, S. (2018). Markedly Deranged Injury Site Metabolism and Impaired Functional Recovery in Acute Spinal Cord Injury Patients With Fever. Crit Care Med.

12. Werndle, M.C., Saadoun, S., Phang, I., Czosnyka, M., Varsos, G.V., Czosnyka, Z.H., Smielewski, P., Jamous, A., Bell, B.A., Zoumprouli, A. and Papadopoulos, M.C. (2014). Monitoring of spinal cord perfusion pressure in acute spinal cord injury: initial findings of the injured spinal cord pressure evaluation study*. Crit Care Med 42, 646-655.

13. Saadoun, S. and Papadopoulos, M.C. (2020). Targeted perfusion therapy in spinal cord trauma. Neurotherapeutics, In press.

14. Jones, C.F., Newell, R.S., Lee, J.H., Cripton, P.A. and Kwon, B.K. (2012). The pressure distribution of cerebrospinal fluid responds to residual compression and decompression in an animal model of acute spinal cord injury. Spine (Phila Pa 1976) 37, E1422-1431.

15. Squair, J.W., Belanger, L.M., Tsang, A., Ritchie, L., Mac-Thiong, J.M., Parent, S., Christie, S., Bailey, C., Dhall, S., Street, J., Ailon, T., Paquette, S., Dea, N., Fisher, C.G., Dvorak, M.F., West, C.R. and Kwon, B.K. (2017). Spinal cord perfusion pressure predicts neurologic recovery in acute spinal cord injury. Neurology 89, 1660-1667.

16. Kwon, B.K., Curt, A., Belanger, L.M., Bernardo, A., Chan, D., Markez, J.A., Gorelik, S., Slobogean, G.P., Umedaly, H., Giffin, M., Nikolakis, M.A., Street, J., Boyd, M.C., Paquette, S., Fisher, C.G. and Dvorak, M.F. (2009). Intrathecal pressure monitoring and cerebrospinal fluid drainage in acute spinal cord injury: a prospective randomized trial. J Neurosurg Spine 10, 181-193. 
17. Scott, D.A. and Denton, M.J. (2016). Spinal cord protection in aortic endovascular surgery. Br J Anaesth 117 Suppl 2, ii26-ii31.

18. Coselli, J.S., LeMaire, S.A., Koksoy, C., Schmittling, Z.C. and Curling, P.E. (2002). Cerebrospinal fluid drainage reduces paraplegia after thoracoabdominal aortic aneurysm repair: results of a randomized clinical trial. J Vasc Surg 35, 631-639.

19. Crawford, E.S., Svensson, L.G., Hess, K.R., Shenaq, S.S., Coselli, J.S., Safi, H.J., Mohindra, P.K. and Rivera, V. (1991). A prospective randomized study of cerebrospinal fluid drainage to prevent paraplegia after high-risk surgery on the thoracoabdominal aorta. J Vasc Surg 13, 36-45; discussion 45-36.

20. Ackerman, L.L. and Traynelis, V.C. (2002). Treatment of delayed-onset neurological deficit after aortic surgery with lumbar cerebrospinal fluid drainage. Neurosurgery 51, 14141421; discussion 1421-1412.

21. Varsos, G.V., Werndle, M.C., Czosnyka, Z.H., Smielewski, P., Kolias, A.G., Phang, I., Saadoun, S., Bell, B.A., Zoumprouli, A., Papadopoulos, M.C. and Czosnyka, M. (2015). Intraspinal pressure and spinal cord perfusion pressure after spinal cord injury: an observational study. J Neurosurg Spine 23, 763-771.

22. Phang, I. and Papadopoulos, M.C. (2015). Intraspinal Pressure Monitoring in a Patient with Spinal Cord Injury Reveals Different Intradural Compartments: Injured Spinal Cord Pressure Evaluation (ISCoPE) Study. Neurocrit Care 23, 414-418.

23. Wagshul, M.E., Eide, P.K. and Madsen, J.R. (2011). The pulsating brain: A review of experimental and clinical studies of intracranial pulsatility. Fluids Barriers CNS 8, 5.

24. Czosnyka, M., Smielewski, P., Timofeev, I., Lavinio, A., Guazzo, E., Hutchinson, P. and Pickard, J.D. (2007). Intracranial pressure: more than a number. Neurosurg Focus 22, E10. 25. Saadoun, S., Werndle, M.C., Lopez de Heredia, L. and Papadopoulos, M.C. (2016). The dura causes spinal cord compression after spinal cord injury. Br J Neurosurg 30, 582-584. 
26. Martirosyan, N.L., Kalani, M.Y., Bichard, W.D., Baaj, A.A., Gonzalez, L.F., Preul, M.C. and Theodore, N. (2015). Cerebrospinal fluid drainage and induced hypertension improve spinal cord perfusion after acute spinal cord injury in pigs. Neurosurgery 76, 461-468; discussion 468-469.

27. Phang, I., Werndle, M.C., Saadoun, S., Varsos, G., Czosnyka, M., Zoumprouli, A. and Papadopoulos, M.C. (2015). Expansion duroplasty improves intraspinal pressure, spinal cord perfusion pressure, and vascular pressure reactivity index in patients with traumatic spinal cord injury: injured spinal cord pressure evaluation study. J Neurotrauma 32, 865-874. 28. Carpenter, K.L., Young, A.M. and Hutchinson, P.J. (2017). Advanced monitoring in traumatic brain injury: microdialysis. Curr Opin Crit Care 23, 103-109.

29. Tamune, H., Takeya, H., Suzuki, W., Tagashira, Y., Kuki, T., Honda, H. and Nakamura, M. (2014). Cerebrospinal fluid/blood glucose ratio as an indicator for bacterial meningitis. Am J Emerg Med 32, 263-266. 


\section{FIGURE LEGENDS}

Fig. 1. Monitoring setup. A. Schematic to illustrate ISP, CSFP and MD monitoring. With the patient lying flat, ISP is monitored by a pressure probe placed subdurally at the injury site and CSFP from a catheter placed in the lumbar CSF space. A MD catheter is also placed next to the pressure probe. B. Typical ISP and CSFP waveforms. P1 percussion peak, P2 tidal peak, P3 dicrotic peak. Examples of ISP and simultaneously-measured CSFP signals over $\mathbf{C}$. $2-3$ seconds and D. 5 minutes.

Fig. 2. ISP versus CSFP. A. Average ISP versus average CSFP for entire monitoring period. Best-fit straight line, $\mathrm{R}=-0.11$. White circles ( $|\mathrm{ISP}-\mathrm{CSFP}| \leq 5 \mathrm{mmHg}$ ), gray circles (CSFP - ISP $>5 \mathrm{mmHg}$ ), black circles (ISP - CSFP $>5 \mathrm{mmHg}$ ). B. Example of ISP signal and simultaneously-recorded CSFP signal, monitored over 10 hours, that correlate (top) poorly and (bottom) well. C. Distribution of running Pearson R between ISP and CSFP for each patient. D. Example of ISP signal and simultaneously-recorded CSFP signal, monitored over 10 seconds, with (left) negative, (middle) positive, and (middle) no correlation. Below are corresponding plots of Pearson R versus time. NS, not significant.

Fig. 3. Physiological parameters computed from ISP versus CSFP. A. Average SCPP computed from CSF $\left(\mathrm{SCPP}_{\mathrm{CSF}}\right)$ versus average $\mathrm{SCPP}$ computed from CSFP (SCPP ISP), $\mathrm{R}=$ 0.39. White circles $\left(\left|\mathrm{SCPP}_{(\mathrm{csf})}-\mathrm{SCPP}_{(\mathrm{ISP})}\right| \leq 5 \mathrm{mmHg}\right)$, gray circles $\left(\mathrm{SCPP}_{(\mathrm{csf})}-\mathrm{SCPP}_{(\mathrm{ISP})}>5\right.$ $\mathrm{mmHg})$, black circles $\left(\mathrm{SCPP}_{(\mathrm{csf})}-\mathrm{SCPP}_{(\mathrm{ISP})}<5 \mathrm{mmHg}\right)$. B. Average sPRx computed from $\mathrm{CSF}\left(\mathrm{sPRx}_{(\mathrm{csf})}\right)$ versus average $\mathrm{sPRx}$ computed from ISP $\left(\mathrm{sPR}_{(\mathrm{ISP})}\right), \mathrm{R}=0.45$. White circles $\left(\left|\mathrm{SPR}_{(\mathrm{csf})}-\mathrm{sPRx}(\mathrm{ISP})\right| \leq 0.05\right)$, gray circles $\left(\mathrm{sPRx}_{(\mathrm{csf})}-\mathrm{sPRx}_{(\mathrm{ISP})}>0.05\right)$, black circles $\left(\mathrm{sPRx}_{(\mathrm{csf})}-\mathrm{sPRx}_{(\mathrm{ISP})}<0.05\right)$. C. Overall $\mathrm{SCPP}_{\mathrm{opt}}$ computed from CSF $\left(\mathrm{SCPP}_{\mathrm{opt}(\mathrm{csf})}\right)$ versus overall SCPP $_{\text {opt }}$ computed from ISP $\left(\mathrm{SCPP}_{\mathrm{opt}(\mathrm{ISP})}\right), \mathrm{R}=-0.22$. White circles $\left(\mid \mathrm{SCPP}_{\mathrm{opt}(\mathrm{csf})}-\right.$ 
$\left.\mathrm{SCPP}_{\text {opt(ISP) }} \leq 5 \mathrm{mmHg}\right)$, gray circles $\left(\mathrm{SCPP}_{\text {opt(csf) }}-\mathrm{SCPP}_{\text {opt(ISP) }}>5 \mathrm{mmHg}\right)$, black circles $\left(\mathrm{SCPP}_{\text {opt(csf })}-\mathrm{SCPP}_{\text {opt(ISP) }}<5 \mathrm{mmHg}\right)$. Best-fit straight lines. $N S$, not significant.

Fig. 4. Biochemical parameters at injury site versus CSF. Plots of MD versus lumbar CSF values with best-fit straight line for $\mathbf{A}$. [Glucose] in $\mathrm{mM}(\mathrm{R}=0.32)$, B. [Lactate] in $\mathrm{mM}(\mathrm{R}=$ 0.0007), C. [Pyruvate] in $\mu \mathrm{M}(\mathrm{R}=-0.12)$, D. Lactate-to-pyruvate ratio - LPR $(\mathrm{R}=-0.05)$, $\mathbf{E}$. [Glutamate] in $\mu \mathrm{M}(\mathrm{R}=0.61)$, and $\mathbf{E}$. [Glycerol] in $\mu \mathrm{M}(\mathrm{R}=0.56)$. Data from 12 patients. $P$ $<0.0001^{\dagger \dagger} ; N S$, not significant.

Fig. 5. Effect of draining lumbar CSF on ISP. A. Setup. With the patient lying flat, ISP is monitored by a pressure probe placed subdurally at the injury site whilst $10 \mathrm{~mL}$ lumbar CSF were drained. B. Examples from two patients (black, red) of ISP traces during draining 10 $\mathrm{mL}$ lumbar CSF. C. Plot of $\triangle \mathrm{ISP}$ as a result of draining $10 \mathrm{~mL}$ lumbar CSF (circles are individual values, lines are means) from $12 / 13$ patients. $P<0.05^{*}, 0.01^{* *}, 0.005^{\#}, 0.001^{\# \#}$, $0.0005^{\dagger} ; N S$, not significant.

Fig. 6. Relation between cord edema and concordance between ISP and CSFP signals. A. T2 mid-sagittal MRI showing length of cord signal change. B. Plot of length of cord signal change in mm versus mean Pearson $\mathrm{R}$ (ISP versus $\mathrm{CSFP}$ ). $\mathrm{R}=0.66, P<0.05$. 
Table 1. Patient demographic characteristics

\begin{tabular}{|c|c|c|c|c|c|c|c|c|c|}
\hline $\begin{array}{c}\text { PATIENT } \\
\text { NO. }\end{array}$ & $\begin{array}{c}\text { AGE } \\
\text { YEARS }\end{array}$ & SEX & SITE & $\begin{array}{c}\text { TYPE OF } \\
\text { SURGERY } \\
\text { POST / } \\
\text { ANT+POST } \\
\end{array}$ & $\begin{array}{l}\text { ADMISSION } \\
\text { AIS GRADE }\end{array}$ & $\begin{array}{l}\text { FOLLOW } \\
\text { UP AIS }\end{array}$ & $\begin{array}{c}\text { DURATION OF } \\
\text { FOLLOW UP } \\
\text { (months) }\end{array}$ & $\begin{array}{c}\text { DURATION OF } \\
\begin{array}{c}\text { MONITORING } \\
\text { (hours) }\end{array} \\
\end{array}$ & $\begin{array}{c}\text { NUMBER OF } \\
\text { SIMULTANEOUS MD and } \\
\text { CSF SAMPLES } \\
\end{array}$ \\
\hline 1 & 67 & $\mathrm{M}$ & $\mathrm{C} 3$ & Post & $\mathrm{A}$ & $\mathrm{A}$ & 1 & 104.25 & 0 \\
\hline 2 & 67 & M & $\mathrm{C} 4$ & Post & $\mathrm{C}$ & $\mathrm{C}$ & 12 & 127.93 & 8 \\
\hline 3 & 32 & M & $\mathrm{C} 4$ & Ant + Post & $\mathrm{C}$ & D & 10 & 150.93 & 3 \\
\hline 4 & 39 & M & $\mathrm{T} 7$ & Post & A & B & 15 & 113.12 & 11 \\
\hline 5 & 35 & M & $\mathrm{C} 4$ & Ant+Post & $\mathrm{C}$ & A & 12 & 84.5 & 7 \\
\hline 6 & 27 & M & L1 & Post & $\mathrm{C}$ & D & 6 & 111.78 & 9 \\
\hline 7 & 50 & $\mathrm{M}$ & $\mathrm{C} 5$ & Post & B & B & 2 & 139 & 14 \\
\hline 8 & 47 & M & $\mathrm{T} 8$ & Post & A & $\mathrm{C}$ & 12 & 105.63 & 9 \\
\hline $9^{*}$ & 57 & M & $\mathrm{C} 4$ & Post & A & A & 3 & 147.15 & 12 \\
\hline 10 & 66 & M & $\mathrm{C} 4$ & Post & A & A & 4 & 128.5 & 12 \\
\hline 11 & 46 & M & $\mathrm{T} 12$ & Post & A & $\mathrm{C}$ & 4 & 51.78 & 3 \\
\hline 12 & 52 & M & $\mathrm{C} 5$ & Ant+Post & A & B & 2 & 127.56 & 12 \\
\hline 13 & 26 & M & $\mathrm{C} 6$ & Ant+Post & A & B & 1 & 70.5 & 8 \\
\hline
\end{tabular}

Ant, anterior; $M$, male; Post, posterior. *Permanent pacemaker so did not have MRI 
Table 2. Complications

\begin{tabular}{lll}
\hline \multicolumn{1}{c}{ COMPLICATION } & $\begin{array}{c}\text { NO. OF } \\
\text { PATIENTS }\end{array}$ & \multicolumn{1}{c}{ COMMENTS } \\
\hline Wound infection & 1 & $\begin{array}{l}\text { Brittle diabetes and E. Coli bacteraemia from urosepsis. } \\
\text { Wound swabs also grew E Coli. Infection eradicated by } \\
\text { wound washout and 6 weeks ceftriaxone. }\end{array}$ \\
CSF Leak around probes & 4 & $\begin{array}{l}\text { All managed with re-suturing of probe exit site with no } \\
\text { further leaks. }\end{array}$ \\
& & $\begin{array}{l}\text { In one patient, lumbar drain stopped transducing a } \\
\text { pressure wave and would not drain nor flush so lumbar } \\
\text { drain was removed. In the second patient, lumbar drain } \\
\text { was re-sited without complication. }\end{array}$ \\
$\begin{array}{l}\text { Lumbar drain blocked } \\
\text { MRI }\end{array}$ & 2 & $\begin{array}{l}\text { All clinically asymptomatic. In 3/6, pseudo- } \\
\text { meningocele resolved on MRI at one year. 3/6 awaiting } \\
\text { one year follow up MRI. }\end{array}$ \\
\hline
\end{tabular}


A

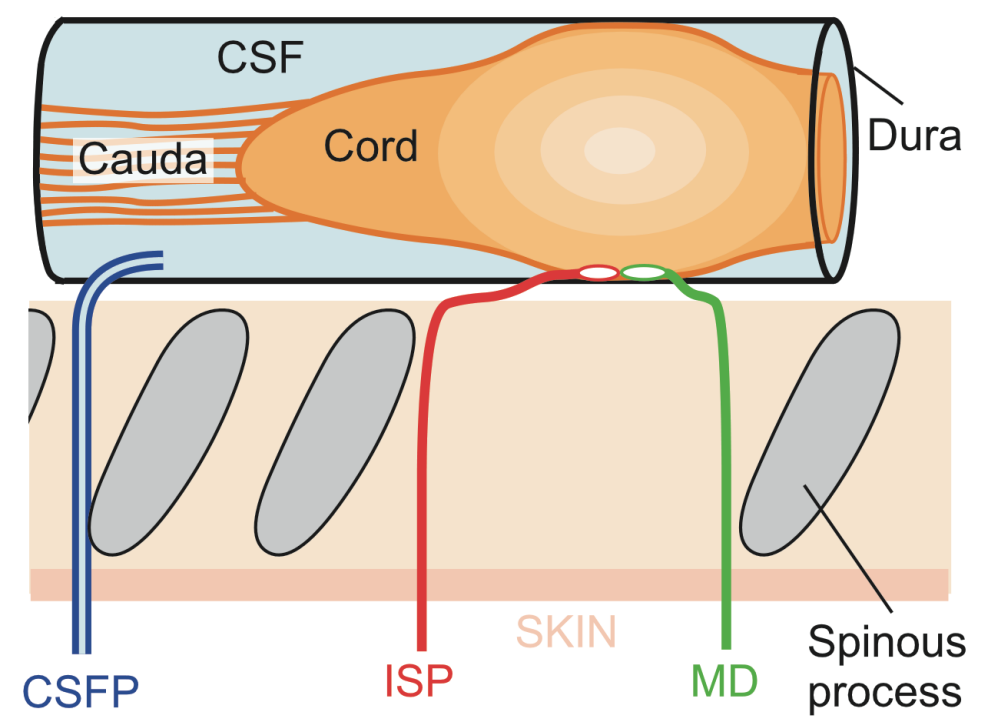

B

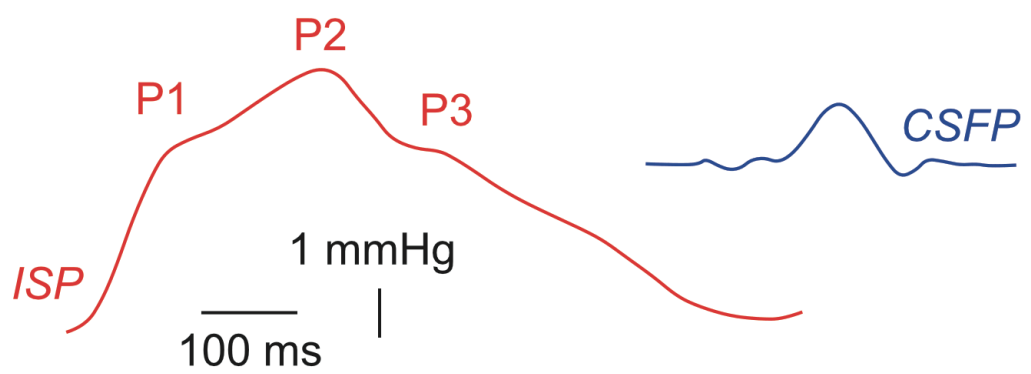

C $m m H g$

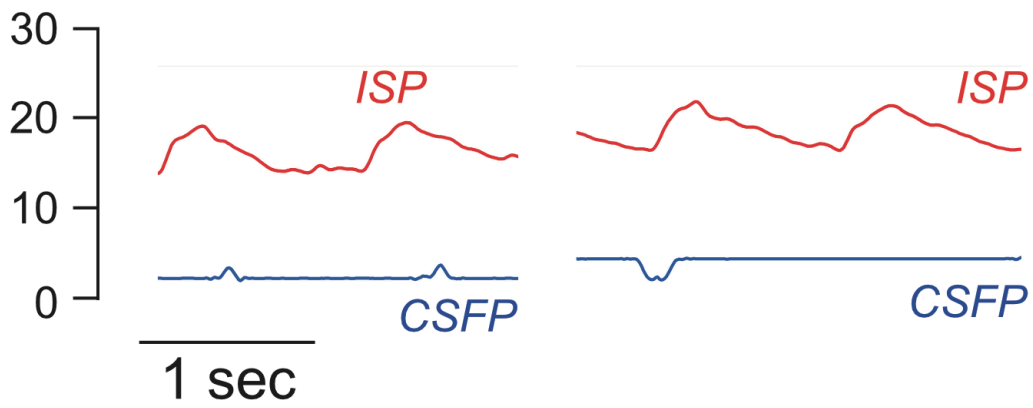

D $\mathrm{mmHg}$

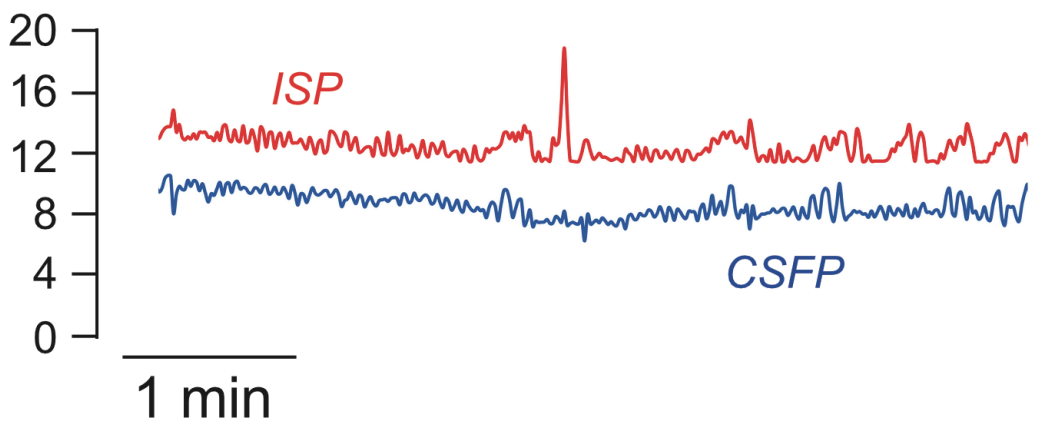


A

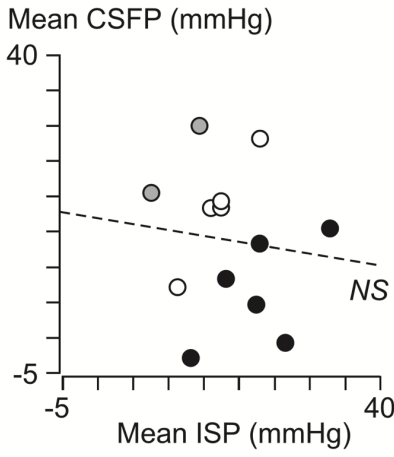

C

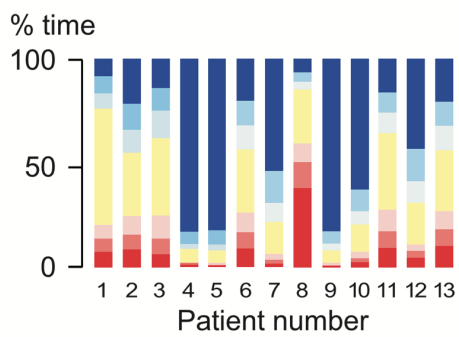

Pearson $\mathrm{R}$

$\underset{-1-.7-5-3}{1} \quad 1 \frac{1}{3.57}$
B
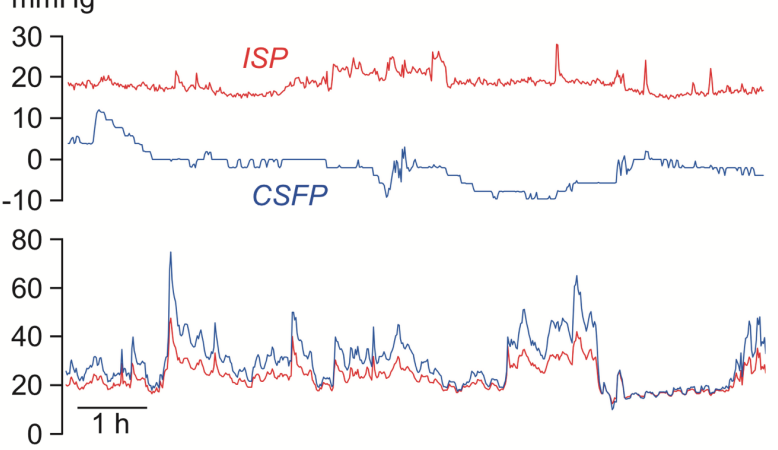

D

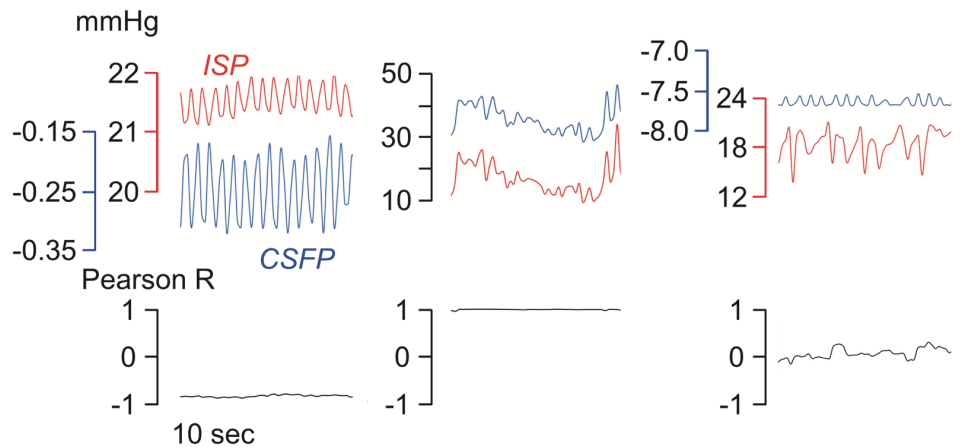

FIGURE 2 
A Mean $\operatorname{sCPP}_{(\mathrm{csf})}(\mathrm{mmHg})$

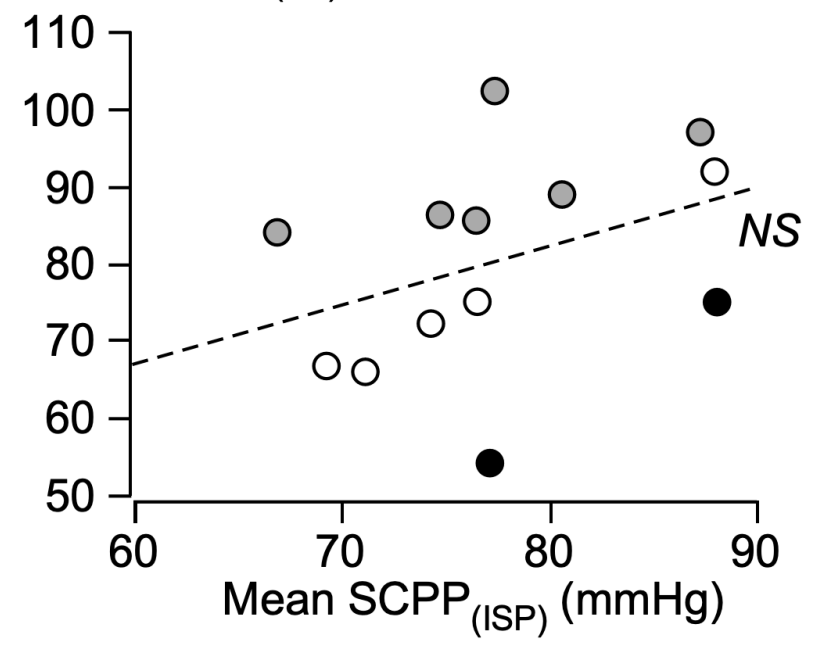

B Mean sPRx ${ }_{(\mathrm{csf})}$

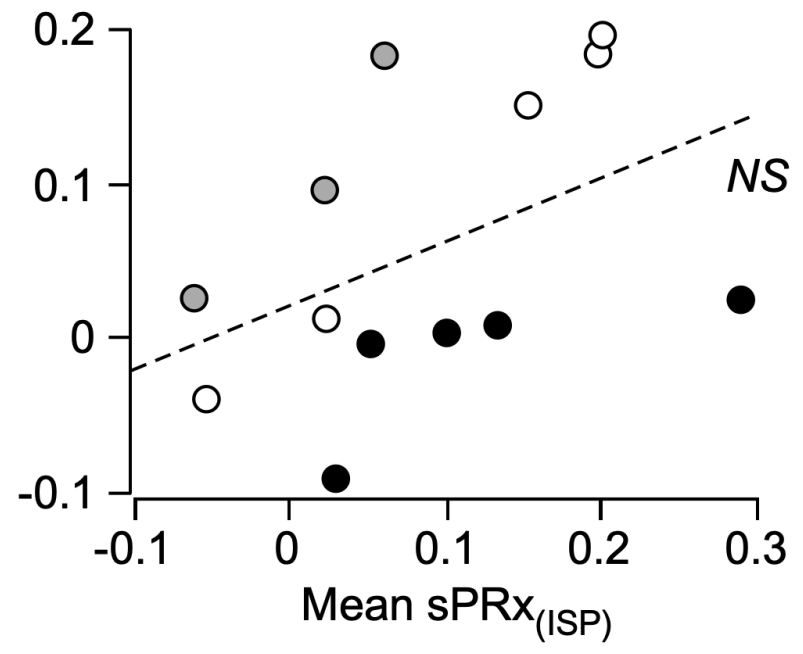

C Mean $\mathrm{SCPP}_{\text {opt (csf) }}(\mathrm{mmHg})$

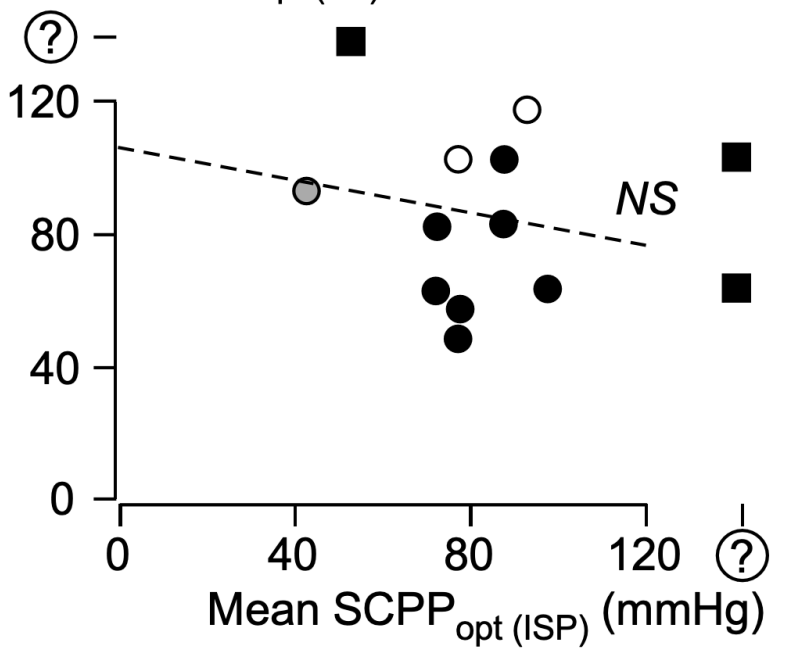


A

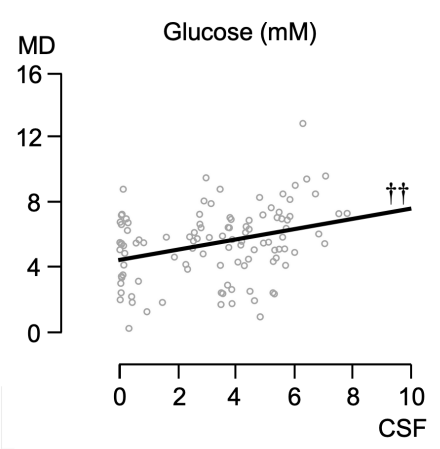

D

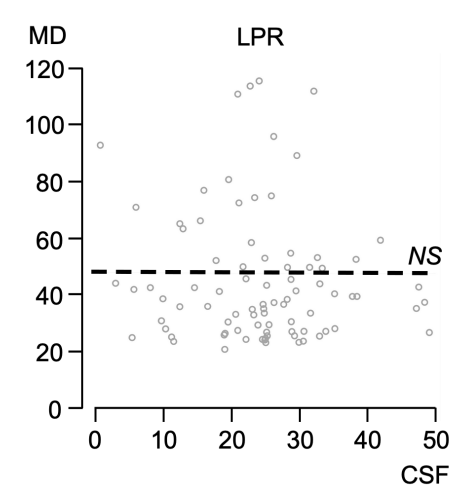

B

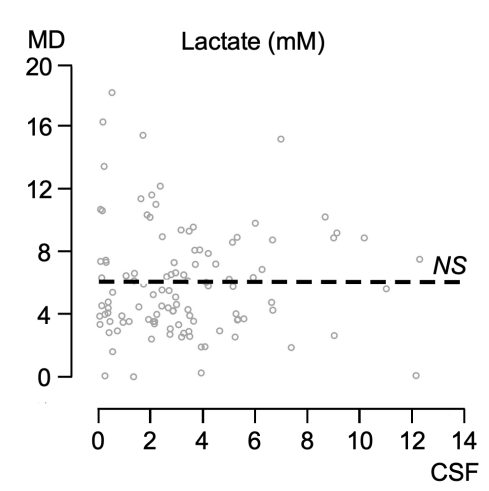

E

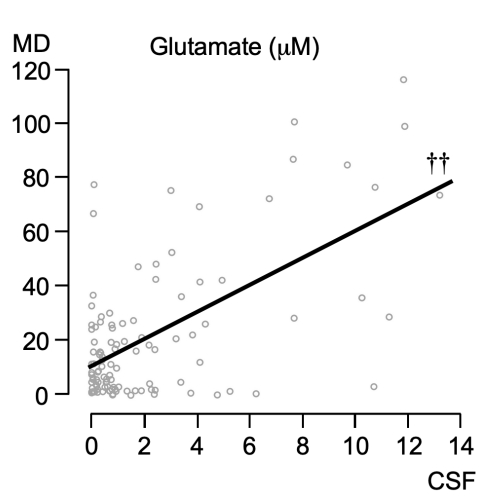

C

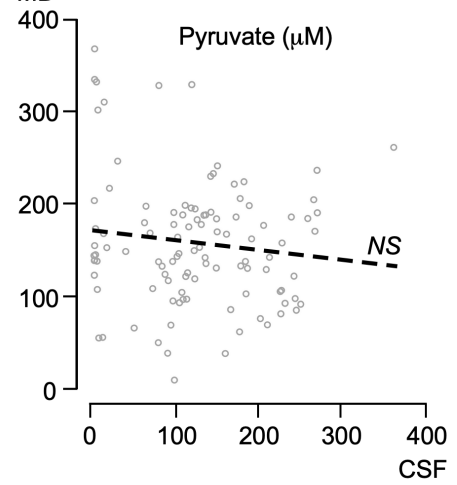

F

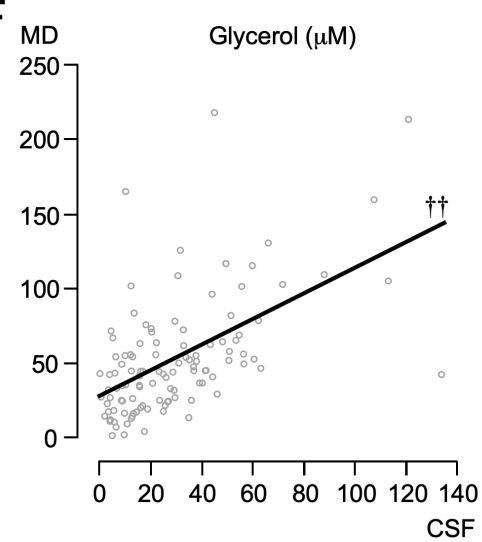

FIGURE 4 
A

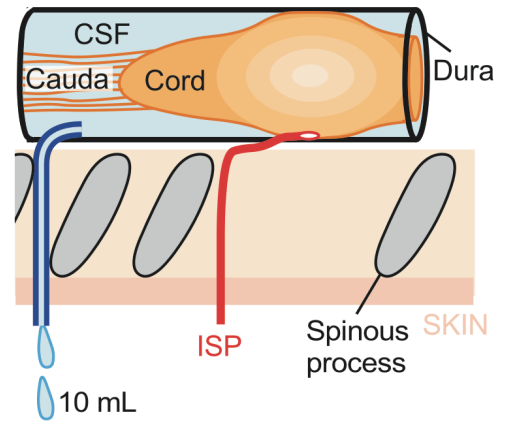

B

ISP $(\mathrm{mmHg})$

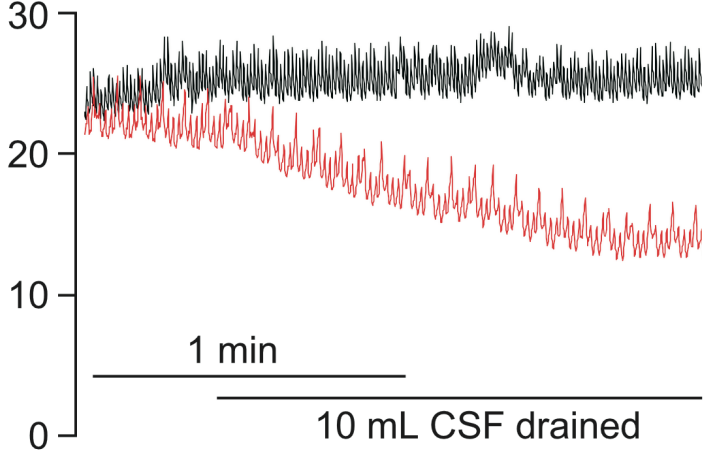

C

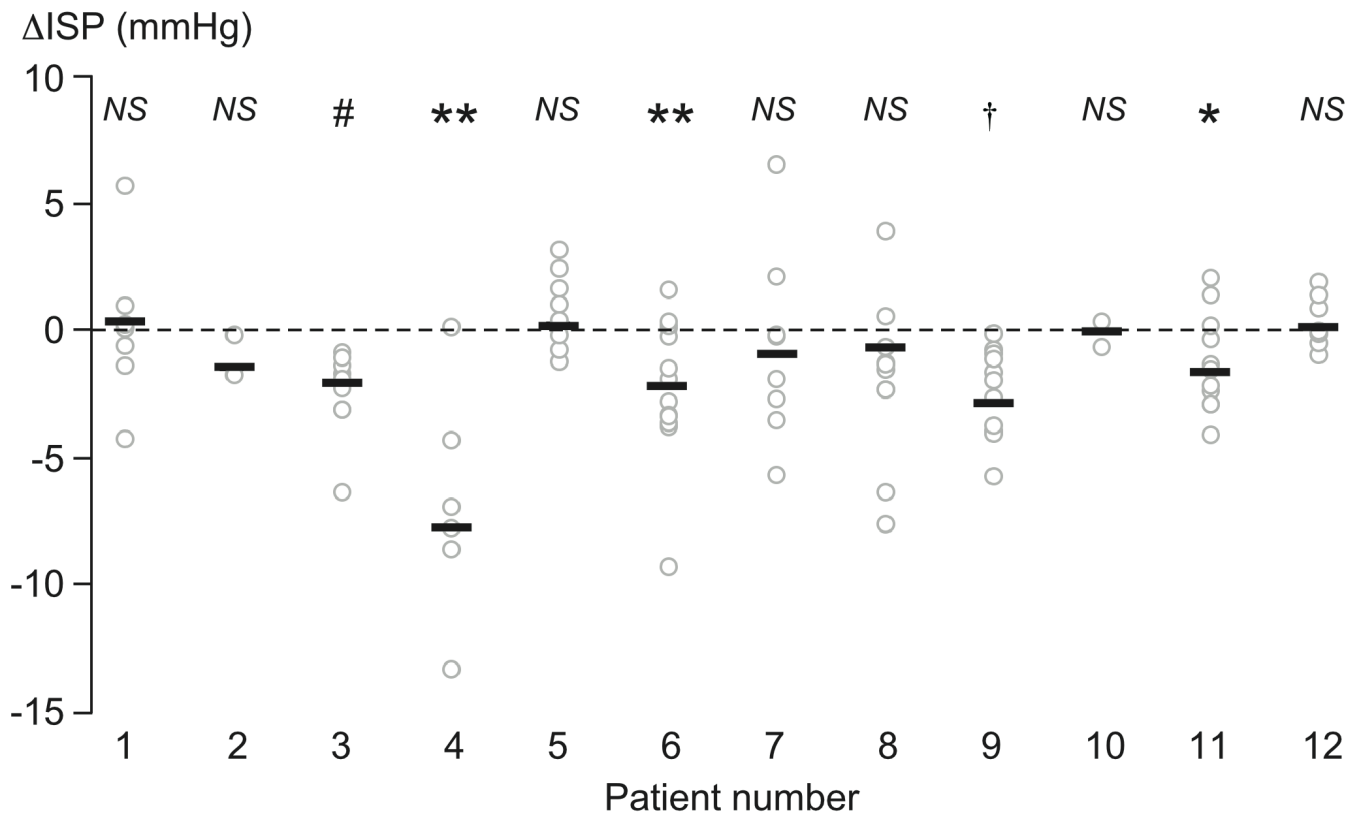

FIGURE 5 


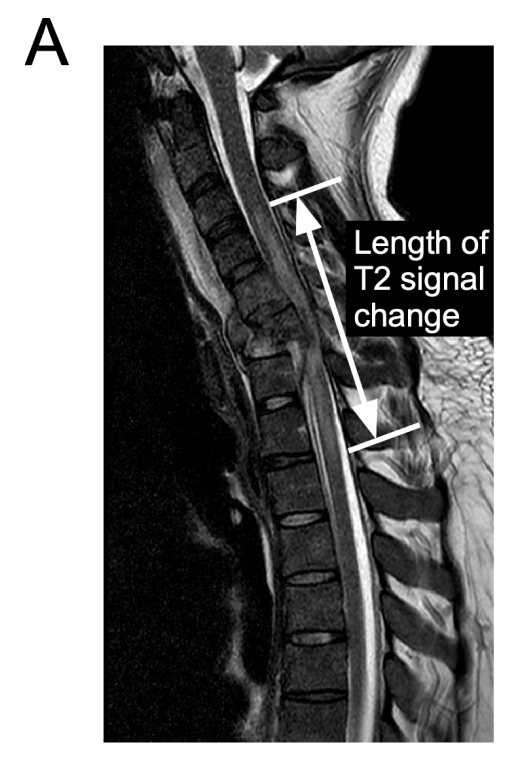

B Length of T2 signal change (mm)

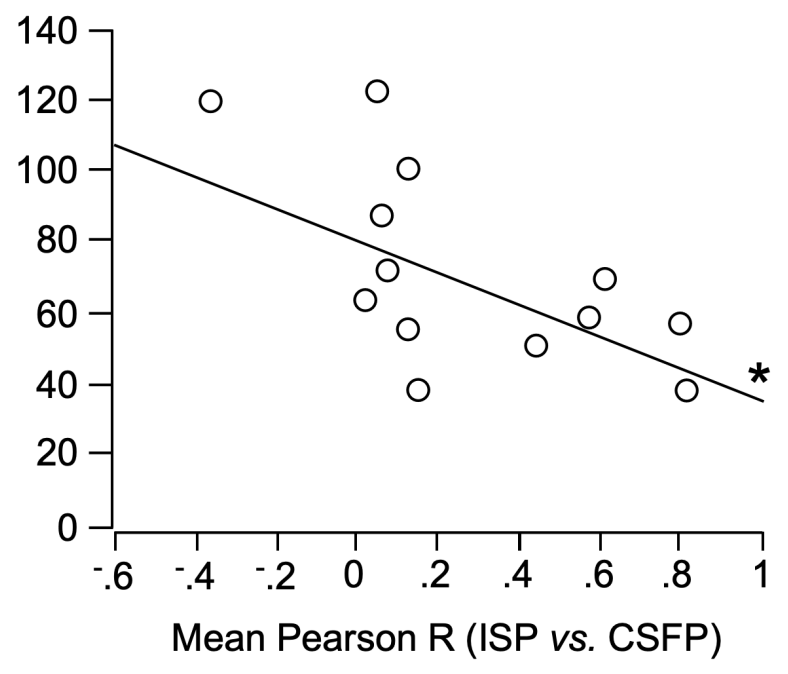

FIGURE 6 


\section{SUPPLEMENT}

Supplement. Further analysis of ISP and CSFP signals. A. FFT of 2-hour long ISP and corresponding CSFP signals showing amplitude spectral density $(\mathrm{mmHg} / \sqrt{\mathrm{Hz}})$ versus frequency (Hz). (top) CSFP signal with no pulsation, (middle) CSFP signal with some pulsation, (bottom) CSFP signal with prominent pulsation. Peaks correspond to respiratory rate (RR), heart rate (HR) and harmonics. B. ISP and CSFP signal characteristics: $\delta \mathrm{P} / \delta \mathrm{T}$ (slope of pulse wave) and $\lambda$ (ISP CSFP latency). C. Plot of mean $\delta \mathrm{P} / \delta \mathrm{T}$ of the CSFP and ISP waveforms for each patient (dot).

Lines are means. D. Plot of mean $\lambda$ for each patient (dot). Lines are means. $P<0.05^{*},<0.001^{\# \#}$
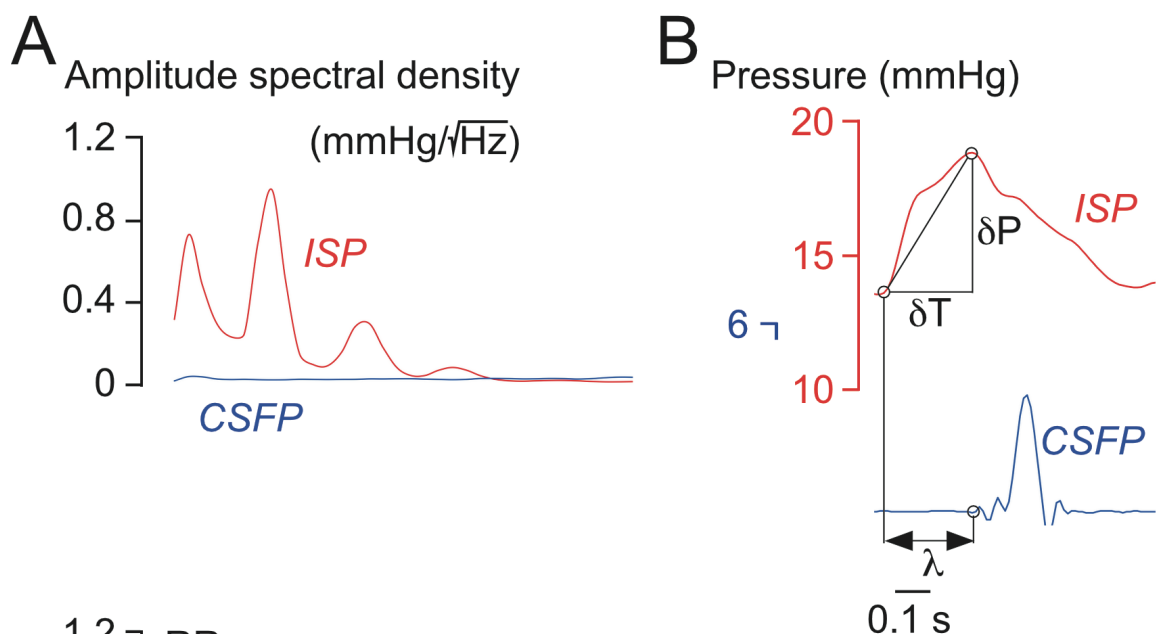

$\mathrm{C}_{\delta P / \delta T}(\mathrm{mmHg} / \mathrm{s})$

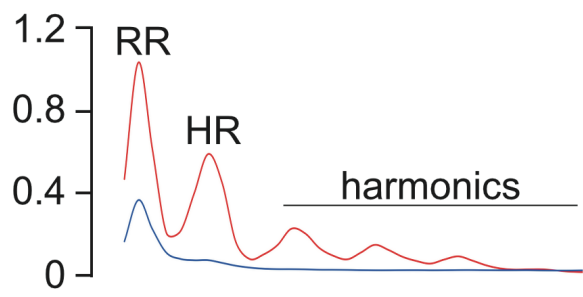

$0 . \bar{s}$

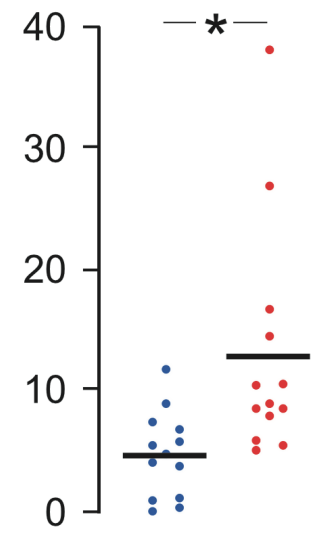

CSFP ISP

D \% waveforms
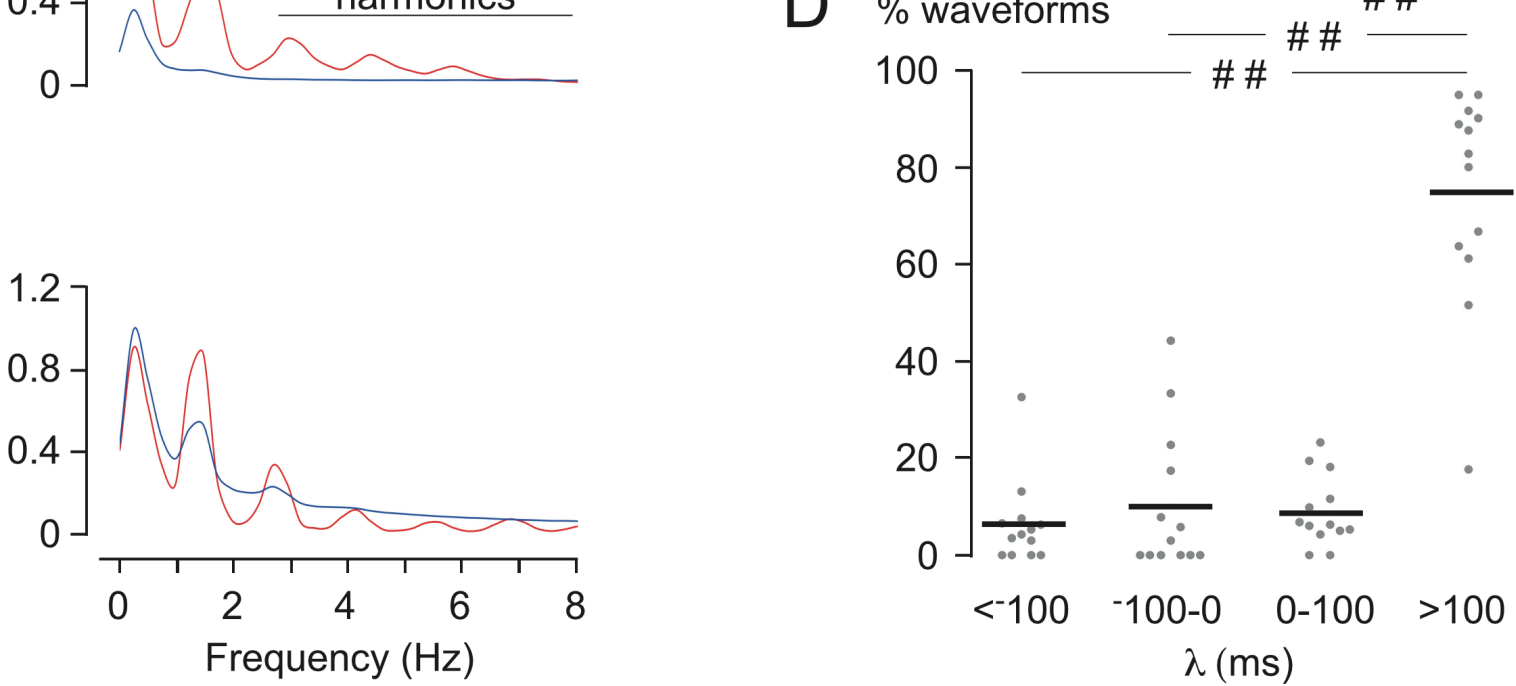

$\lambda(\mathrm{ms})$ 